\title{
Preliminary results on interleukin- 4 and interleukin-10 cytokine production in malnourished, inducible nitric oxide synthase- deficient mice with schistosomiasis mansoni infection
}

\author{
Renata P Ramos/ ${ }^{+++}$, Vlaudia MA Costa*, Camila F Melo/ ${ }^{++++}$, Valdênia MO Souza*, \\ Elizabeth Malagueño*, Eridan M Coutinho, Frederico G C Abath/ ${ }^{++}$, \\ Silvia ML Montenegro/ ${ }^{+}++$
}

\author{
Departamento de Imunologia, Laboratório de Bioquímica e Biologia Molecular, Centro de Pesquisas Aggeu \\ Magalhães- Fiocruz, Av. Prof. Morais Rego s/nº, Cidade Universitária, 52020-020 Recife, PE, Brasil \\ *Laboratório de Imunopatologia Keizo Asami, UFPE, Recife, PE, Brasil
}

Schistosoma mansoni infected C57Bl/6 inducible nitric oxide synthase (iNOS)-deficient and non-deficient malnourished mice, both fed a balanced controlled diet were studied. Interleukins, IL-4 and IL-10 responses to soluble egg antigens (SEA) 90 days after infection, were determined. Our results suggest that in iNOS deficient, malnourished mice, 90 days after of infection, nitric oxide has a downregulating effect on IL-4 and IL-10 production. We are currently investigating the biological significance of these findings.

Key words: Schistosoma mansoni - cytokines - malnutrition - mice

In Northeastern Brazil, a large number of people infected with Schistosoma mansoni suffer from malnutrition. The mouse model is appropriate to investigate aspects relating to the pathogenesis of the association of schistosomiasis and malnutrition about which little is known (Coutinho et al. 1992).

The inhibition of iNOS (inducible nitric oxide synthase), the enzyme responsible for the formation of nitric oxide (NO), resulted in cachexia and exacerbated hepatic pathology, suggesting that, in schistosomiasis NO limits hepatocyte damage (Brunet et al. 1999, Abath et al. 2006). However, another group (Patton et al. 2002) observed that infected wild mice developed a Th2 profile response and chronic liver disease, while the interleukin (IL-4) deficient mice developed a Th1 profile response with high levels of $\mathrm{NO}$ and interferon (IFN- $\gamma$ ) and an acute lethal syndrome deriving from the absence of the Th2 response and wellstructured granuloma. This study presents preliminary results on the production of IL-4 and IL-10 in mice deficient in the production of nitric oxide syntase (KOiNOS) and in control C57BL/6 wild type (WT) mice, subjected to hypoproteic diets (Region Basic Diet-RBD) or a normal diet and infected or not with S. mansoni, in an effort to correlate the production of these cytokines with the function of NO.

Financial support: Capes, Facepe, Fiocruz

${ }^{+}$Corresponding author: silvia@cpqam.fiocruz.br

${ }^{++} \mathrm{CNPq}$ research scholarships

${ }^{+++}$Capes fellowship

${ }^{++++}$Pibic/Fiocruz fellowship

Received 25 May 2006

Accepted 26 June 2006
Male 21-day old C57BL/6 mice, deficient in iNOS (KOiNOS) were used along with control mice. The mice were obtained from Fiocruz and kept in the CPqAM animal facilities. All the procedures involving the mice were approved by ethical committees for the use of animals (CEUA/Fiocruz, P0201/03). A S. mansoni strain isolated from Belo Horizonte $(\mathrm{BH})$ and kept in our laboratory was used. Mice were infected percutaneously with 30 cercariae shed from Biomphalaria glabrata. Malnutrition was induced by administering a RBD diet, based on the dietary standards of the human population in areas where schistosomiasis is endemic in the Northeast (Coutinho et al. 1992). The KOiNOS group was subdivided into infected malnourished (KOiNOS IM), $\mathrm{n}=10$, and infected eutrophic mice (KOiNOS IE), $\mathrm{n}=10$. The WT group was likewise subdivided into: infected malnourished (WT IM), $\mathrm{n}=10$, and infected eutrophic (WT IE), $n=10$. After 90 days of infection, the mice were anaesthetized and sacrificed and their spleens were removed and processed. The spleen cells obtained from a pool of three mice per group were cultivated in RPMI 1640 containing 10\% FCS (fetal calf serum), and stimulated by SEA (soluble egg antigens) at a concentration of $20 \mu \mathrm{g} / \mathrm{ml}$ or phorbol myristate acetate (PMA)/ionomycin $(20 \mu \mathrm{g} / \mathrm{ml})$, for $48 \mathrm{~h}$, at $37^{\circ} \mathrm{C}$ under $5 \%$ $\mathrm{CO}_{2}$ and the supernatants were collected for quantification of IL-4 and IL-10, using the ELISA (enzyme-linked immunosorbent assay).

Statistical significance was determined using Student's two-tailed $t$ test and significance was assumed for a $p$ value $<0.05$.

iNOS is present in virtually all cells, and is expressed in response to proinflammatory cytokines, such as IFN- $\gamma$, tumor necrosis factor (TNF- $\alpha$ ) and IL $-1 \beta$, resulting in the prolonged production of large ammounts of NO (Brunet et al. 1999). In contrast, IL-4 can inhibit NO production by upregulating arginase expression thereby providing an alternative pathway for metabolism of L-arginine, the precursor for NO (Patton et al. 2002). On the other hand, the 


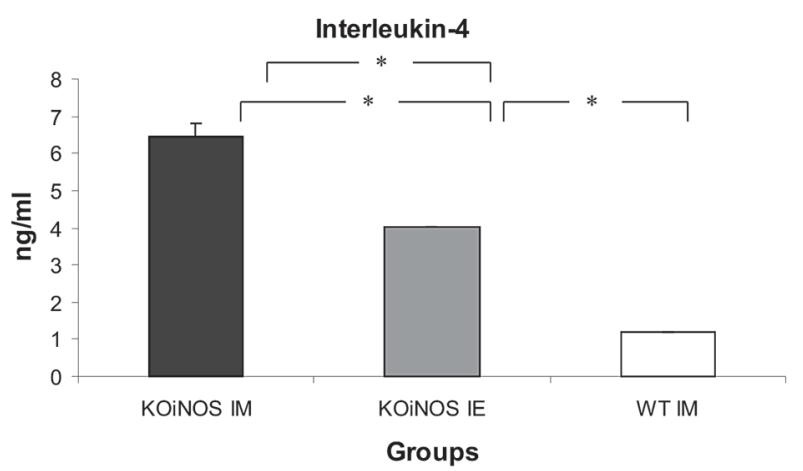

Fig. 1: interleukin-4 (ng/ml) levels in spleen cells from inducible nitric oxide synthase deficient infected malnourished mice (KOiNOS IM), inducible nitric oxide synthase deficient infected eutrophic mice (KOiNOS IE) and wild type infected malnourished mice (WT IM) 90 days after Schistosoma mansoni infection. Spleen cells were stimulated with soluble egg antigens; $* \mathrm{p}<0.05$.

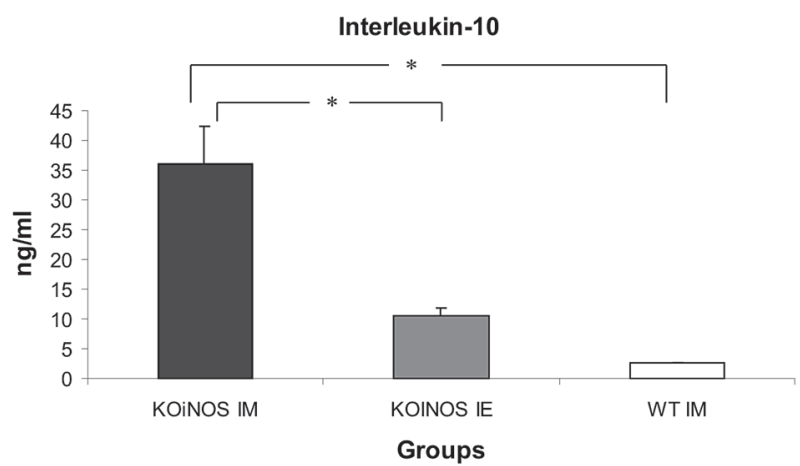

Fig. 2: interleukin-10 (ng/ml) levels in spleen cells from inducible nitric oxide synthase deficient infected malnourished mice (KOiNOS IM), inducible nitric oxide synthase deficient infected eutrophic mice (KOiNOS IE) and wild type malnourished infected mice (WT IM) 90 days after Schistosoma mansoni infection. Spleen cells were stimulated with soluble egg antigens; $* \mathrm{p}<0.05$.

effects of iNOS on cytokine production is less clear. In the present communication, the effects of disrupture of the gene encoding iNOS on cytokine production was investigated in eutrophic or malnourished S. mansoni infected mice.
The mice from the KOiNOS IM group, after 90 days of infection, produced more IL-4 and IL-10 than the KOiNOS IE group $(\mathrm{p}<0.05)$. Comparing the KOiNOS IM group with the WT IM group, over the same period, the levels of IL-4 and IL-10 were lower in the WT IM group $(p<0.05$, Figs 1,2). Although there have been several reports demonstrating that NO is capable of inhibiting cytokine production by T cells (Patton et al. 2002), the effects on selective Th1 or Th2 responses is still contradictory. Our results suggest that both iNOs deficiency and malnutrition enhance the Th2 response, possibly by down-regulating Th1 cytokines. Furthermore, it seems that these situations (iNOS defficiency and malnutrition) act synergistically.

In order to analize if the diet and the presence of $\mathrm{NO}$ enhance the production of IL-10 and IL-4 cytokines, we are repeating the experiment and increasing the number of animals per group to obtain more significant values and comparisons. In addition, we are currently investigating the biological consequences of these findings for granuloma formation and patology.

\section{ACKNOWLEDGEMENTS}

To Luiz Carlos Figueiredo and Wlademir Gomes de Melo for technical support.

\section{REFERENCES}

Abath FGC, Morais CNL, Montenegro CEL, Wynn TA, Montenegro SML 2006. Immunopathogrnic mechanisms in schistosomiasis: what can be learnt from human studies? Trends Parasitol 2: 85-91.

Brunet LR, Beall M, Dunne DW, Pearce EJ 1999. Nitric oxide and the th2 response combine to prevent severe hepatic damage during Schistosoma mansoni infection. J Immunol 163: 4976-4977.

Coutinho EM, Freitas LPCG, Abath FGC 1992. The influence of the regional basic diet from Northeast Brazil on health and nutritional conditions of mice infected with Schistosoma mansoni. Rev Soc Bras Med Trop 25: 13-20.

Patton EA, La Flamme AC, Pedras-Vasconcelos JA, Pearce EJ 2002. Central role for interleukin-4 regulating nitric oxidemediated inhibition of T-cell proliferation in schistosomiasis. Infect Immun 70: 177-194. 